\title{
CRIATIVIDADE E DESENVOLVIMENTO DE COMPETÊNCIAS GERENCIAIS EM EMPRESAS DE BASE TECNOLÓGICA
}

\section{CREATIVITY AND DEVELOPMENT OF MANAGERIAL COMPETENCE IN TECHNOLOGY-BASED COMPANIES}

\author{
Luiz Da Costa Alves Filho \\ Universidade Federal de Campina Grande - PB \\ luizfilhu@hotmail.com \\ Anielson Barbosa da Silva \\ Universidade Federal da Paraíba - UFPB \\ anielson@uol.com.br \\ Henrique Muzzio \\ Universidade Federal de Pernambuco - UFPE \\ henrique.muzzio@ufpe.br
}

Submissão: $15 / 12 / 2017$

Aprovação: 15/03/2019

\begin{abstract}
RESUMO
Este estudo buscou compreender a percepção dos gestores de empresas de base tecnológica (EBTs) sobre as implicações da criatividade no desenvolvimento de competências gerenciais. A pesquisa utiliza uma abordagem qualitativa e foi realizada com nove gestores de EBTs participantes da Incubadora Tecnológica de Campina Grande-PB no Brasil. Os resultados da pesquisa revelaram que os gestores percebem um vínculo significativo e quase indissociável entre criatividade e inovação. Os achados ainda possibilitaram a identificação de alguns fatores que fomentam a criatividade e que demandam dos gestores abertura para obter insights, capacidade de geração de ideias, promoção de soluções criativas para a empresa, além de facilitar o relacionamento interpessoal, o gerenciamento de conflitos e as expectativas entre as partes interessadas. Conclui-se que o ambiente das EBTs promove o desenvolvimento de competências gerenciais vinculadas à liderança, à visão de futuro e a comunicação para lidar com a natureza dinâmica da inovação e do ambiente tecnológico.
\end{abstract}

Palavras-chave: Criatividade; Competências Gerenciais; Empresas de Base Tecnológica; Incubadora Tecnológica; Brasil. 


\begin{abstract}
This study aims to understand the perception of managers of Technology-based companies (TBCs) on the implications of creativity in the development of managerial competences. The research uses a qualitative approach and was held with nine TBCs managers participants of the Technology Incubator of Campina Grande, Paraíba, in Brazil. The survey results revealed that managers perceive a significant and almost inseparable link between creativity and innovation. The findings still allowed the identification of some factors that foster creativity and that demand opening of the managers to gain insights, ideas generation capability, promotion of creative solutions for the enterprise, in addition to facilitating interpersonal relationship, conflict management and expectations among stakeholders. It is concluded that the environment of the TBCs promotes the development of managerial competence related to the leadership, the future vision and to deal with the dynamic nature of innovation and the technological environment.
\end{abstract}

Key-words: Criativity; Managerial Competences; Technology based-companies, Technological Incubator, Brasil. 


\section{INTRODUÇÃO}

As organizações atuam em um ambiente que demanda um nível significativo de dinamicidade para dar respostas às expectativas mercadológicas e sociais, isto é, oferecer uma maior qualidade nos produtos e serviços, com preços equivalentes aos benefícios gerados, alternativas para os novos hábitos de consumo, percepção de valor por parte dos consumidores e, consequentemente, obter melhores desempenhos operacionais.

Nesse contexto, os gestores precisam investir em novos conhecimentos para garantir a sobrevivência de suas organizações e/ou melhorar o seu posicionamento no setor em que atuam, por meio da aplicação de novos valores para as empresas. A rapidez com que as mudanças ocorrem é um fator crucial no impulso da capacidade criativa das pessoas, pois as demandas das organizações potencializam a geração de novas ideias, fomentando o empreendedorismo e a elaboração de produtos e processos inovadores (SARQUIS et al., 2015). Contudo, é necessário que os gestores enfrentem seus receios e estejam abertos para este novo cenário, estimulando nos indivíduos novas formas de pensar, realizar suas atividades e encontrar soluções cada vez mais eficientes (FELDMAN; RUTHES; CUNHA, 2008; MIETZNER; KAMPRATH, 2013).

Além disso, a criatividade tem sido reconhecida como fundamental no desenvolvimento tecnológico das organizações e socioeconômico dos países, em virtude do seu potencial inovador, uma vez que o saber criativo das pessoas pode torná-las mais competentes nas suas atividadess, auxiliando não apenas o processo de geração e transformação de ideias em inovações, como também o gerenciamento de equipes, de projetos, de pessoas e de recursos (MUZZIO; PAIVA JÚNIOR, 2018).

Para fomentar o desenvolvimento de soluções inovadoras e sustentáveis em empresas de base tecnológica (EBTs), é necessário identificar e desenvolver competências necessárias para viabilizar a gestão destes empreendimentos. A noção de competência tem evoluído ao longo do tempo a partir de várias perspectivas conceituais. Contudo, uma das das definições que enfatiza a criatividade concebe a competência como "um conjunto de conhecimentos, habilidades e atitudes necessárias para que a pessoa desenvolva suas atribuições e responsabilidades usando da criatividade e inovação" (FELDMAN; RUTHES; CUNHA, 2008, p.240), as quais devem ser desenvolvidas em um ambiente propício para a mobilização, a combinação e a integração das competências na ação (LE BOTERF, 2003).

Nas empresas de base tecnológica, por exemplo, há um maior estímulo e reconhecimento em relação aos colaboradores que buscam desenvolver novas ações, uma vez que o pensamento criativo de cada um pode ser traduzido em forma de algum produto ou serviço que a sociedade necessita e a empresa pode oferecer (PORTER, 1990). Nesse contexto, entender como se dá o vínculo entre a criatividade e o desenvolvimento de competências gerenciais nas EBTs foi o desafio e a motivação para conduzir este estudo, pois, numa economia baseada em conhecimento, as empresas de base tecnológica assumem um papel relevante para o desnevolvimento de novos produtos e serviços, como também uma estratégia para a competitividade de um espaço territórial.

De acordo com a Associação Nacional de Entidades Promotoras de Empreendimentos Inovadores (ANPROTEC, 2011), o Brasil possui mais de 380 incubadoras - associações que oferecem apoio a estes empreendimentos a fim de potencializar suas ideias e transformá-las em ações concretas em busca do sucesso empresarial -, que englobam cerca de 2.600 empresas, gerando mais de 16 mil oportunidades de trabalho.

Entre os mais de 70 polos tecnológicos no Brasil, um deles está localizado na cidade de Campina Grande, Paraíba; trata-se do Parque Tecnológico da Paraíba (PaqTcPB), o qual 
foi escolhido como o contexto deste estudo, desenvolvido na Incubadora Tecnológica de Campina Grande (ITCG). No momento em que esta pesquisa foi realizada, 17 empresas, divididas em empresas incubadas (9) e empresas associadas (8) faziam parte da ITCG.

Este artigo tem como objetivo compreender a percepção dos gestores de EBTs sobre as implicações da criatividade no desenvolvimento de competências gerenciais. A realização do estudo sobre o tema é relevante pela possibilidade de ampliar a compreensão de um fenômeno que possui o petencial de impacto socioeconômico crescente quando vislumbramos uma sociedade cada vez mais vinculada à tecnologia para a produção de conhecimento e para a oferta de bens e serviços. Além disso, os resultados do estudo podem servir de base para a formação de gestores de EBTs de outros contextos ou ainda de empresas que atuam em ambiente inovadores, o que amplia o escopo do objetivo aqui proposto.

\section{REFERENCIAL TEÓRICO}

O potencial competivo das organizações foi, durante muito tempo, dependente de sua capacidade em lidar com os recursos materiais e de produção para atender alguma demanda. No entanto, em um contexto de crescentes transformações, a fonte de poder passou a ser fruto da informação, do potencial criativo, inovador, útil e eficiente desenvolvido pelas organizações (DE MASI, 2005). As empresas passaram e ainda estão vivenciando um processo de transição, ou seja, de um foco mais restrito ao operacional para um foco nas pessoas e seus conhecimentos como um meio de alcançar melhores resultados e vantagem competitiva em relação aos concorrentes.

A criatividade, fundamental nesse processo de transição, é considerada um fenômeno complexo, multifacetado e que abrange a construção de conhecimento a partir de várias abordagens, podendo envolver a natureza do pensamento criativo, as características distintivas de uma pessoa criativa, o desenvolvimento da criatividade ao longo do tempo e os ambientes mais fortemente relacionados com atividades criativas (SIMONTON, 2000).

Entende-se a criatividade como a capacidade de produzir um trabalho que é novo e valioso (AMABILE, 1998). O novo significa incomum, único, original, que rompe com os padrões existentes e contribui com algo que não havia antes; valioso, indica que o produto atende a uma necessidade ou resolve um problema, é útil, serve a um propósito e contribui para a sociedade; contudo, a criatividade é servida em um ambiente favorável para o seu desenvolvimento e que acolhe novas ideias (MARTENS, 2011), isto é, empresas com culturas estritamente regulamentadoras dificilmente impulsionarão a sua capacidade criativa (ANDRON, 2013).

Nesse sentido, é importante mobilizar esforços para propiciar um ambiente que potencialize a capacidade criativa nas pessoas, e isso inclui levar em consideração aspectos não só relacionados à estrutura física, mas também uma boa relação interpessoal na organização. Investir na interação dos indivíduos - com pessoas de outras culturas, se possível - tem sido um fator relevante para a inovação, uma vez que é capaz de promover mudanças de hábitos que poderiam inibir o seu potencial criativo (MADDUX et al., 2009).

Para tanto, sugere-se que uma reestruturação organizacional bem-sucedida seja realizada a partir da incorporação de passos gradativos que sensibilizem os indivíduos sobre os novos comportamentos capazes de resultar em mudanças e benefícios reais para empresa, a partir da ampliação de sua produtividade (ANDRON, 2013). Assim, será possível nutrir a sua cultura com um perfil dinâmico e flexível, o qual se exige das organizações contemporâneas em busca do sucesso. 
O processo de geração de ideias fornece uma base para o entendimento das implicações da criatividade no trabalho, a partir do envolvimento natural que emerge dos indivíduos à medida que são dadas as condições necessárias. Entretanto, o trabalho criativo demanda dos indivíduos a necessidade de definir um problema, reunir informações, gerar e aperfeiçoar as ideias iniciais e planejar a sua implementação (BYRNE et al., 2009). De acordo com os mesmos autores, para fomentar e conduzir a aplicação com sucesso de uma ideia criativa, uma combinação significativa entre a motivação intrínseca e os recursos do meio é essencial, pois ao mesmo tempo em que esse trabalho está sendo desenvolvido, também está demandando recursos da organização.

Nessa perspectiva, evidencia-se que as caracterísitcas das pessoas criativas demandam dos gestores algumas condições, uma vez que as pessoas criativas têm sua identidade vinculada ao seu trabalho e às realizações decorrentes dele, que estão intimamente associadas e geralmente são motivadas pela realização e o reconhecimento profissional (MUMFORD; GUSTAFSON, 1988). Para potencializar a criatividade, as organizações devem fomentar uma gestão compartilhada para que os conhecimentos sejam disseminados e os funcionários aumentem suas competências e a capacidade de criação em equipe (LEE et al., 2015). Desenvolver a criatividade na equipe é um conceito abrangente, que inclui novos processos em um ambiente de trabalho interativo e requer, dentre outros, a melhoria da comunicação, o estabelecimento de estruturas flexíveis, a partilha dos objetivos e o compartilhamento de conhecimento (ANDRON, 2013; RAWUNG; WURYANINGRAT; ELVINITA, 2015).

O papel dos gerentes que lidam com contextos criativos é desafiar fundamentalmente as formas existentes de agir no contexto organizacional (BERG, 2016), pois diariamente são confrontados com uma série de dilemas que exigem um equilíbrio entre as ações diferentes, e as habituais (ANDERSEN; KRAGH, 2013). Isso demanda o desenvolvimento de competências gerenciais para lidar com um ambiente criativo inovador.

\subsection{Competências gerenciais}

Nas sociedades antigas, a competência era percebida apenas como uma forma de julgamento de um indivíduo em relação ao que o outro era capaz de realizar. Com o passar do tempo, passou a ser entendida como a capacidade de lidar com as contingências de uma determinada situação (PEREIRA, 2010).

Neste novo cenário, as empresas têm o desafio não só de encontrar, mas também de reter profissionais preparados para lidar com os riscos de um contexto em constante mudança. A noção de competência emerge como uma forma de fazer as organizações, por meio de seus gestores, tornarem-se capazes de lidar com as adversidades e mobilizar seus recursos em contextos geralmente pouco previsíveis (RUAS; ANTONELLO; BOFF, 2005; MIETZNER; KAMPRATH, 2013).

Para Dutra (2004), pode-se dividir essa contextualização histórica em quatro momentos: o primeiro, associado à ideia de vinculação das pessoas ao cargo, isto é, selecionálas e desenvolvê-las nas posições que mais pudessem produzir; o segundo momento aborda os aspectos inerentes às funções, como a sua complexidade, a fim de atribuí-las aos indivíduos mais aptos para exercê-las; o terceiro diz respeito à integração entre a gestão e a estratégia organizacional, buscando alinhar os objetivos da organização com os de seus colaboradores, aumentando o comprometimento; por fim, o quarto momento consiste na apropriação dos conceitos de competências pelas pessoas, o que envolve tanto o aprimoramento dos sistemas de gestão de pessoas pelas empresas, como também uma maior responsabilidade das pessoas no estabelecimento de seus planos de carreira e desenvolvimento profissional. 
Ao longo do tempo, o conceito foi ganhando novas abordagens, especificamente na Europa, onde a competência é percebida como a capacidade de saber fazer na ação (LE BOTERF, 2003; BÜNDCHEN; ROSSETTO; SILVA, 2011). O desenvolvendo de novas habilidades ocorre por meio de um aperfeiçoamento contínuo, cuja finalidade é mobilizar adequadamente os recursos de maneira a apoiar o alcance dos objetivos da organização. Como reforça Le Boterf (2003), a noção de competência envolve a capacidade de combinar recursos incorporados ao indivíduo e recursos advindos do meio.

Já Zarifian (2001) trata o conceito como uma capacidade que vai além da qualificação do indivíduo e, que envolven três dimensões concernentes ao âmbito gerencial nas empresas: noção de evento (o que acontece de forma imprevisível, não programada, inesperada), enfatizando a ideia de desenvolvimento contínuo e não apenas pontual; noção de comunicação (criar um link entre os envolvidos no projeto, compartilhar interesses e alinhar os objetivos dentro da organização); noção de serviço (reconhecer a importância de atender tanto às necessidades dos clientes internos como externos), fator importante e que deve ser desenvolvido junto à comunicação.

Uma outra perspectiva abrange o nível organizacional e foi adodata por Prahalad e Hamel (1995), na qual a competência é um conjunto de habilidades que a organização precisa mobilizar para criar oportunidades, a fim de obter produtos e serviços que gerem competividade para a organização.

Em nível gerencial, desenvolver competências se tornou um diferencial diante das incertezas que envolvem o contexto contemporâneo (PEREIRA; SILVA, 2011), o que demanda dos gestores a capacidade de combinar conhecimentos, valores, atitudes, habilidades em determinado contexto e de seu processo de desenvolvimento como uma construção pessoal integrativa (SCHACHTER et al., 2015).

Uma competência gerencial pode ser entendida como uma aptidão adquirida para mobilizar o saber, o saber agir e o saber ser, necessários na prática gerencial (LE BOTERF, 2003; BUCKLEY, STORINO; SAARNI, 2003) e se desenvolvem na ação, por meio dos conhecimentos e experiências adquiridos pelo indivíduo e pela sua capacidade de mobilizar a sua equipe. Para Zarifian (2001), competência gerencial refere-se ao saber lidar com as contingências e incertezas de um determinado ambiente, com o devido conhecimento; são aquelas que buscam colocar em prática as necessidades da organização e dos seus colaboradores, utilizando-se dos conhecimentos, habilidades e atitudes dos envolvidos para alcançar os objetivos propostos (RUAS; ANTONELLO; BOFF, 2005). No entanto, para que as competências sejam entendidas como gerenciais, é necessário que o gestor consiga utilizálas de forma a mobilizar os recursos - tangíveis e intangíveis - e obter resultados para organização. Se isso não ocorre, devem ser consideradas apenas competências individuais (RUAS, 2001).

De acordo com Fischer, Fleury e Urban (2008), a prática gerencial é fundamental nesse processo de estímulo ao desenvolvimento de competências e criatividade, e os gestores devem refletir (ARANDIGA; TORTOSA, 2000) sobre como promover um novo arranjo organizacional capaz de fundamentar tais condições e como incentivar mudanças de crenças e valores, discutindo interesses e perspectivas sociais e culturais entre os colaboradores alinhadas a estratégias organizacionais para aumentar a competitividade da empresa no setor em que está atuando.

O ambiente das empresas de base tecnológica (EBTs) apresenta características que demandam o desenvolvimento de competências gerenciais porque são caracterizadas pelo dinamismo, criatividade e inovação inerente às cobranças por novidades do setor em que 
atuam. Tais cobranças são, por sua vez, advindas dos novos hábitos de consumo desenvolvidos nas sociedades contemporâneas.

\subsection{Empresas de base tecnológica (EBTs)}

No setor de alta tecnologia, em que as empresas são obrigadas a introduzir novos produtos e processos - com certa periodicidade - derivados de ideias criativas dos seus colaboradores, a inovação torna-se uma resultante da competência de seus gestores em agir sobre estas ideias para fazer alguma diferença específica e tangível no domínio em que ocorre (SCHACHTER et al., 2015).

De acordo com Baer (2012), embora ainda exista alguma resistência ao fomento de um ambiente idealmente propício à criatividade, estudos que analisaram as condições que determinam quando as ideias desenvolvidas são convertidas em aplicações reais demonstram que as empresas que mais investem nesse aspecto são as de tecnologia. Isso ocorre porque nas EBTs há a necessidade de utilização constante de conhecimentos técnico-científicos de seus colaboradores nos projetos da empresa, e que são percebidos como os seus principais ativos (MIETZNER; KAMPRATH, 2013).

Além disso, as EBTs já nascem envolvidas em um contexto de intensa competitividade e, para conseguir sobreviver e atuar eficientemente nesse mercado, é fundamental dar as devidas condições para que os indivíduos se sintam motivados e estimulados a expressarem de forma concreta a sua criatividade (SEO; CHAE; LEE, 2015), o que contribui para o desenvolvimento de uma cultura criativa, assim como a geração de ideias tendem a surgir e, consequentemente, ocorre a transformação de uma ideia em um produto, serviço ou processo.

Um dos primeiros conceitos de EBTs foi sugerido por Marcovitch, Santos e Dutra (1986), indicando que tais empresas são projetadas para criar produtos ou serviços por meio de um elevado conteúdo tecnológico. Para Mello et al. (2006), empresas baseadas em tecnologia são aquelas em que o conhecimento é a sua principal matéria-prima e a busca por novas alternativas tecnológicas e inovadoras está sempre alinhada aos seus produtos. De acordo com Belli (2008), configuram-se como aquelas que se utilizam em sua essência organizacional de recursos tangíveis e intangíveis para desenvolver produtos e serviços à luz de ideias e processos novos em sua tecnologia.

Segundo Cortes et al. (2005), as EBTS passaram a ser objeto de interesse de pesquisadores pela necessidade de aprofundar o entendimento sobre suas características e o seu fortalecimento no mercado.

As empresas de base tecnológica são empreendimentos com um forte potencial tecnológico que, por meio de seus colaboradores, aplicam conhecimentos e desenvolvem novas técnicas ou funcionalidades nos seus produtos e serviços, seja aprimorando algo já existente no mercado ou introduzindo novas alternativas para as existentes. A definição e a caracterização de EBTs ainda é polissêmica. Em geral, estas empresas são estruturalmente pequenas e possuem um forte potencial em pesquisa e desenvolvimento, pois estão constantemente adaptando-se às novas tendências de seu contexto de atuação.

Alguns aspectos que facilitam a sua identificação envolvem: (i) a gestão partilhada da empresa, que envolve, em média, 3 a 5 pessoas trabalhando no mesmo projeto; (ii) a independência da empresa, por exemplo, não fazer parte de coligações ou franquias e; (iii) a motivação gerada pela realização de uma ideia potencialmente inovadora (BOLLINGER; HOPE; UTTERBACK, 1983). 
Ademais, percebe-se como uma EBT aquela que oferece produtos e serviços que são frutos da aplicação de conhecimentos técnicos e inovadores (BARBOSA; HOFFMANN, 2013) e que se diferencia das outras empresas, num primeiro momento, por envolver um baixo número de colaboradores - mão de obra - e uma alta capacidade técnica e intelectual. São empresas em que o produto final advém do desenvolvimento de pesquisas e aplicações cuja tecnologia representa um significativo valor agregado (WOLFFENBÜTTEL, 2001).

As reflexões teóricas discutidas ratificam que os vínculos entre a criatividade e o desenvolvimento de competências gerenciais em empresas de base tecnológica é um fenômeno com potencial de contribuição para enfrentar os desafios, a singularidade do processo gerencial e a capacidade de impulsionar novos métodos propulsores da inovação.

\section{PROCEDIMENTOS METODOLÓGICOS}

Strauss e Corbin (2008, p. 23) ressaltam a necessidade de abordar nos estudos sobre gestão aspectos relacionados a "experiências vividas, comportamentos, emoções e sentimentos, e também à pesquisa sobre o funcionamento organizacional, movimentos sociais, fenômenos culturais e a interação [...]", os quais permitem ao investigador captar os significados por meio do contato com o entrevistado. A pesquisa parte do princípio que "o conhecimento é construído pelo indivíduo, que percebe o mundo em sua realidade que não é objetiva" (SILVA, 2009, p.148).

Considerando a natureza do objetivo e a característica do fenômeno a ser analisado, optou-se pela realização de uma pesquisa qualitativa, uma vez que permite compreender como o indivíduo desenvolve o conhecimento a partir de uma investigação mais livre acerca do fenômeno estudado (BURRELL; MORGAN, 1979), ou seja, o pesquisador e os investigados interagem com o menor distanciamento possível; sendo assim, o percurso mais coerente para sua compreensão (MERRIAM, 2009).

Para a realização desse estudo, foi selecionado como contexto da pesquisa as Empresas de Base Tecnológica da Incubadora Tecnológica de Campina Grande-PB (ITCG), localizada na Fundação Parque Tecnológico da Paraíba (PaqTcPB). A ITCG dá suporte ao desenvolvimento de empreendimentos inovadores que buscam transformar ideias em ações úteis por meio de processos, produtos e serviços balizados por uma visão de inovação sustentável. Integravam a ITCG, em 2015, 17 empresas, que estão divididas em empresas incubadas e empresas associadas. A escolha desta instituição foi motivada tanto por sua atuação na área de tecnologia quanto pela sua relevância para o desenvolvimento tecnológico, econômico e social do Estado da Paraíba e a sua parceria com universidades, características que lhe conferem um status de caso significativo em seu contexto.

Os sujeitos da pesquisa foram os gerentes das EBTs da ITCG. Inicialmente, foi feito um contato prévio com a coordenadora do PaqTcPB para verificar o consentimento à realização da pesquisa. Após este processo, a coordenadora da incubadora disponibilizou uma planilha com todas as empresas disponíveis e os respectivos e-mails e telefones para contato dos gestores. Um dos autores deste estudo entrou em contato com os seus gestores.

$\mathrm{O}$ acesso aos gestores foi feito pessoalmente, por e-mail e telefone. Foram entrevistados 9 gestores ( 8 homens e 1 mulher) de 8 EBTs, uma vez que em uma das empresas duas pessoas participaram da entrevista. Em relação ao perfil dos gestores, constatou-se que as áreas de formação envolvem computação (2), engenharia (4), design (1), jornalismo (1) e estatística (1). Essa diversidade de áreas foi considerada um aspecto relevante 
para o estudo, pois possibilita maiores reflexões sobre o contexto, a formação e atuação profissional de seus gestores.

O processo de coleta de dados ocorreu por meio de uma entrevista semiestruturada, que permite "captar o dito e o não dito, os significados, os sentimentos, a realidade experimentada pelo entrevistado" (VERGARA, 2009, p. 5). Foi elaborado um termo de consentimento para esclarecer aos participantes os procedimentos éticos para a condução do estudo, sobretudo a não identificação dos sujeitos e das empresas, além de indicar que os dados seriam utilizados apenas para fins desta pesquisa.

As entrevistas foram realizadas entre os meses de outubro e novembro de 2015 , as quais tiveram uma duração média de 44 minutos. Os dados coletados foram transcritos na integra e como estratégia para a análise de dados foi utilizada a análise de conteúdo (AC). Este método é amplamente aplicado nos estudos qualitativos em Administração e proporciona ao pesquisador ir além da compreensão de mensagens expressas por terceiros, pois reconhece qual é o seu sentido em um determinado contexto. De acordo com Bardin (2011), a AC apresenta algumas etapas relevantes no seu processo de estruturação, e que foram seguidas nessa pesquisa, são elas: (i) análise prévia: permite organizar as ideias e sistematizá-las a partir de intuições e operações para o desenvolvimento da análise; (ii) exame do material coletado: referente à aplicação ordenada das decisões tomadas anteriormente; podendo ser resumida em decodificações e identificações dos achados; e, por fim, (iii) o tratamento, a inferência e a interpretação, as quais transformam os dados brutos em dados válidos, com reais significados e informações para o seu desenvolvimento em relação aos objetivos da pesquisa.

À medida que emergiram os significados do material coletado, outro processo foi iniciado: agrupar e direcionar os discursos. A partir de reflexões destes achados, foram identificadas suas respectivas dimensões utilizadas na análise dos dados: (a) o papel da criatividade no contexto gerencial de EBTs e; (b) o vínculo entre competências gerenciais e criatividade em EBTs. Os resultados da pesquisa são apresentados a seguir.

\section{RESULTADOS DA PESQUISA}

\subsection{O papel da criatividade no contexto gerencial de EBTs}

$\mathrm{Na}$ visão dos gestores das EBTs, a criatividade é uma característica com a qual algumas pessoas podem nascer, mas que também pode - e é mais comum - que desenvolvam ao longo de sua trajetória pessoal e profissional, o que evidencia uma condição social da criatividade (BYRNE et al., 2009; LEE et al., 2015), fundamental no mundo coletivo que define as organizações. Assim, faz com que o gestor se torne um diferencial, isto é, seja considerado não apenas um símbolo à frente da empresa, mas aquele que enxerga e desperta em seus colaboradores novos horizontes no contexto profissional.

...a você sair desse quadrado e fazer essas coisas. Foi o que aconteceu com o cara, todo mundo vendia bala do mesmo jeito, aí ele trouxe uma forma singela, simples, praticamente sem custo, mas engraçada, aí issso fez com que se diferenciasse, saíssse em vários veiculos de comunicação e que vendesse muito mais, que era o grande objetivo dele. Então a criatividade ajuda a você se diferenciar dos outros, a você fazer coisas diferentes. [G6] 
Os achados revelaram ainda que a criatividade contribui para melhorar as relações interpessoais na empresa e é considerada um dos elementos cruciais no gerenciamento das pessoas (individualmente), da equipe, dos conflitos e das tomadas de decisão em conjunto (BERG, 2016). Outros aspectos sobre a criatividade estão associados à tomada de decisões para superar situações adversas, isto é, aplicando os conhecimentos de acordo com a dinâmica que o contexto exige, como ressaltaram Schachter et al (2015). Observando o relato abaixo, evidencia-se a necessidade que os gestores têm de enfrentar e superar condições críticas na ação profissional para garantir a prosperidade da empresa.

Então ele tem que ser criativo pra sair de situações constrangedoras, situações ruins... por exemplo, "ah, deu um problema ou então o produto tá dando problema há uma semana”, ele tem que ter jogo de cintura, tem que ter criatividade pra poder acalmar o cliente, pra poder lidar com esse tipo de situação.. [G8]

Além disso, os gestores mencionaram que a criatividade pode fomentar a sensibilidade das pessoas, tanto dos gestores quanto dos seus colaboradores e clientes, fazendo com que as pessoas visualizem elementos que normalmente passam despercebidos, seja nos produtos oferecidos ou nas ações diárias que as pessoas têm e podem servir como exemplo para as outras.

... a criatividade ajuda pra você criar sensilbidade nas pessoas, uma sensibilidade às vezes de comoção, de dar uma estética, um sentimento pra aquela pessoa, então a criatividade tem um papel muito fundamental nisso, de você conseguir soluções que as pessoas geralmente não veem, porque as pessoas vivem num quadrado e aí a criatividade ajuda a você tirar isso [G6]

Este achado está em conformidade com uma das constatações de Amabille (1998). Nessa perspectiva, constata-se, também, que a criatividade é um elemento fundamental nos resultados coletivos das empresas, uma vez que influencia diretamente as ações desenvolvidas, tais como: gerenciar equipes, identificar lacunas, propor soluções e desenvolver sensibilidade nos envolvidos, à medida que gera novas atitudes e agrega valor para os colaboradores e consequentemente para os clientes finais (MIETZNER; KAMPRATH, 2013).

Os discursos reforçam a contribuição que a criatividade pode ter no alcance da vantagem competitiva e no processo de inovação organizacional, a partir da visão de que a criatividade tem potencial para superar um paradigma ou uma prática organizacional obsoleta. Esse reconhecimento pelos respondentes coaduna com percepção de Andersen e Kragh (2013) sobre $\mathrm{o}$ papel preponderante dos gerentes na adequação organizacional às demandas emergentes do mercado, realidade ainda mais significativa no contexto das EBTs (BELLI, 2008). A próxima seção analisar os vínculos entre competências gerenciais e criatividade.

\subsection{O vínculo entre competências gerenciais e criatividade em EBTs}

No contexto das EBTs pesquisadas, os gestores indicaram os papéis gerenciais vivenciados no contexto profissional. Tais papéis estão vinculados a duas perspectivas: (a) 
gerenciar os recursos - principalmente intangíveis - da empresa e; (b) desenvolver ações empreededoras e de administração geral. No primeiro caso, o gerenciamento busca fortalecer os laços entre as pessoas envolvidas a partir de uma gestão integrativa de parcerias, aberta a ouvir, discutir e tomar decisões em comum, mobilizando esforços para captar os recursos necessários para atender às expectativas da empresa e seus stakeholders, no intuito de agregar valor para todas as partes e, consequentemente, alcançar os objetivos desejados.

Bom, eu acho que é gerenciar os seus recursos, pra mim, recursos é o funcionário que ele tem, é o parceiro. Por exemplo, eu não tenho colegas sócios, eu não tenho mais colaboradores, mas eu tenho bastante parceiros, então pra mim, gerenciar esses parceiros, fazer com que eles tragam valor pra minha empresa, e que minha empresa gere valor pra eles, pra mim, esse é o papel, na hora que eu tô sendo o gestor da empresa, eu tô basicamente gerindo esses parceiros. [G4]

Esse depoimento exemplifica uma postura gerencial que é condizente com uma prática criativa. A literatura (ANDERSEN; KRAGH, 2013; LEE et al., 2015) reconhece a importância do indivíduo em seu grupo para gerar inovação. As EBTs se configuram como organizações baseadas no conhecimento. Nesse sentido, ao valorizar o funcionário como um parceiro para o negócio, o entrevistado reconhece a perpesctiva tácita da criatividade e a necessidade de um ambiente organizacional (SEO; CHAE; LEE, 2015) distinto das práticas gerenciais conservadores e inflexíveis.

Ainda nesta perspectiva do papel dos gestores de EBTs, verifica-se que há um direcionamento mais alinhado à capacidade empreendedora e de administração da empresa como um todo. Esta percepção converge com a constatação de Sarquis et al. (2015) de que o setor tecnológico impacta significativamente na forma como as empresas são geridas, pois fomenta o empreendedorismo e aumenta o potencial para elaboração de produtos inovadores. Percebe-se nos discursos que os gerentes tendem a desenvolver uma visão holística para resolver os assuntos administrativos, burocráticos etc., e ter insights do mundo externo, tentando amenizar as incertezas do mercado (Zarifian, 2001), identificar oportunidades viáveis e mobilizar o que for necessário para colocar em prática o que foi planejado.

A questão do gerente, ele tem que ser primeiro bem visionário. Eu costumo geralmente associar um gerente, no caso, de TI, com um surfista, que às vezes tá lá na beira da praia, e tá olhando o mar e ele pressente onde tá se formando a onda, vai, se posiciona num momento adequado pra poder pegar aquela onda, se não a onda passa e você perdeu. Então, tem que ter essa questão de enxergar mais na frente, então a criatividade ajuda muito nisso. [G2]

Estar à frente de uma empresa requer múltiplas competências gerenciais para desempenhar esse papel de maneira eficiente. As várias atividades exigem dos gestores a capacidade de refletir sobre prioridades e mobilizar pessoas e materiais para realizar o que foi pensado. $\mathrm{O}$ discurso anterior exemplifica a condição subjetiva da gestão no contexto criativo, por muitas vezes, sem um roteiro a ser seguido. Diante desse cenário, evidencia-se a importância do conhecimento adquirido com a experiência e o desenvolvimento de 
competências (BÜNDCHEN; ROSSETTO; SILVA, 2011) capazes de permitir aos gestores lidar com a dinâmica desse tipo de negócio.

\subsubsection{Competências necessárias na atividade gerencial em EBTs}

Questionados acerca das competências necessárias à atividade gerencial em EBTs, os gestores afirmaram ter inúmeras atribuições dentro das empresas. No entanto, um aspecto identificado nos discursos gerenciais e que merece destaque aborda uma questão mais "subjetiva" da natureza humana na ação gerencial.

O que isto significa? Que elementos como perseverança, força de vontade, inspiração, atitude, enfrentamento do medo, tolerância, ousadia, persistência, coragem e educação são questões importantes que emergem antes mesmo da efetiva criação do negócio e acompanhaos em todos os seus momentos gerenciais. Bitencourt e Barbosa (2010) reforçam que o aperfeiçoamento contínuo dos profissionais é premissa básica para desenvolver novas habilidades e acompanhar um ambiente altamente volátil.

\section{Ser flexível, saber ouvir e ter bastante perseverança. [G1]}

...é importante que tenha liderança, tolerância, seja compreensível com a equipe... persistência, perseverança, a coragem também, ousadia, tudo isso faz parte né? Então são requisitos importantes. [G7]

Percebe-se que os relatos indicam um conjunto de aspectos abstratos da mente humana que influenciam o desenvolvimento das atividades gerenciais dos entrevistados. Portanto, os indivíduos têm de trabalhá-los para que não desencadeiem situações críticas no seu desempenho na empresa.

Espera-se que os indivíduos tenham o autocontrole necessário para gerir suas emoções e a do grupo, e saber lidar com as diversas situações - momentos de tensão - que encaram ao longo de sua vida, isto é, devem ser capazes de refletir sobre seus pensamentos e ajustar a cada situação (ARANDIGA; TORTOSA, 2000). Já para Buckley, Storino e Saarni (2003), as competências emocionais podem ser alcançadas por meio da identificação e diferenciação emocional, uma vez que podem ajudar as pessoas a: a) traçar seus objetivos; b) enfrentar os desafios; c) gerenciar o emocional de modo que favoreça o envolvimento em estratégias eficazes de solução de problemas; d) perceber o que os outros sentem e ter empatia sobre tais condições e; e) perceber como a comunicação influencia nas relações e emoções.

Por outro lado, os conhecimentos técnicos também foram citados como essenciais no contexto de empresas de base tecnológica, uma vez que grande parte dos gestores atuam no desenvolvimento dos produtos da empresa, que geralmente são frutos das formações específicas, as quais eles detêm e de que se utilizam para planejar e executar tais atividades.

Ele tem que ter conhecimento técnico mínimo... pra saber com o que ele tá lidando... [G8]

Eu vi um livro que dizia que toda empresa tinha que ter três porquinhos, o porquinho administrador, o porquinho técnico e um porquinho visionário, certo? É uma metáfora... então dentro da empresa você tendo esses três perfis profissionais, você consegue sucesso. [G5] 
Como podemos observar, a parte técnica nos processos gerenciais se mantém presente na preocupação gerencial em função das características dessas organizações, dando a ideia de ser um elemento intrínseco ao contexto das EBTs. Contudo, foi evidenciado por alguns gestores que aspectos associados ao clima organizacional podem se sobressair às aptidões funcionais propriamente ditas das pessoas, pois trabalhar em um ambiente desfavorável ou com pessoas que não sabem lidar com diferenças pode resultar negativamente nos resultados da empresa e até na sua imagem frente ao mercado. Assim, faz-se necessário um ambiente de tolerância nas relações e atividades de cada um dos colaboradores no dia-a-dia da vida empresarial (DE MASI, 2005).

\subsubsection{A criatividade como competência gerencial de EBTs}

Frente à complexidade e às diversas abordagens que tanto a criatividade quanto as competências têm, decidiu-se compreender, à luz do discurso de gestores de EBTs, possíveis divergências ou similaridades entre os termos. Assim sendo, com exceção dos gestores (G1, G3.1 e G3.2) de duas empresas, que não souberam ao certo afirmar até que ponto a criatividade conduziria a uma competência gerencial, os demais entrevistados apontaram que ser criativo é realmente uma competência do gestor.

Não tem como avaliar, é uma coisa que... [G3.1] ...então assim, eu acho que é necessário que ele pelo menos busque né, tá inovando e criando dentro da empresa... eu acho que na função que ele tem ali, de tá à frente, de tá liderando, eu acho que é necessário que ele seja criativo... [G3.2] ...ou então que seja proativo, porque se não tiver essa criatividade, que ele busque inovar, buscar soluções fora, alguma coisa...[G3.1] Então eu acho assim, quando você tá fazendo o que você gosta, você busca, por mais que você não seja criativa, mas você busca inovar, você busca criar, você busca estimular sua criatividade de alguma maneira, seja pesquisando, seja indo pra feiras... enfim... de alguma maneira. [G3.2]

Os discursos refletem a complexidade do fenômeno. Apesar disso, não refutam a possibilidade de considerarem a criatividade como uma competência gerencial, pelo contrário, sugerem a criatividade como um recurso para quem está à frente de projetos e pessoas nas empresas. Nessa perspectiva, o gestor deve ser capaz de prospectar e integrar diversas habilidades (MUZZIO; PAIVA JÚNIOR, 2018), a fim de criar um ambiente polivalente e superar o desempenho esperado pela empresa. Caso contrário, estará desenvolvendo e obtendo resultados apenas das competências individuais (LE BOTERF, 2003).

Sendo assim, os gestores asseguram ser necessário alinhar o potencial criativo com outras qualidades que contribuam para um aprendizado constante, como, por exemplo: ser proativo, estar sempre participando de feiras, entrar em contato com pessoas experientes e ter insights para inovar e/ou encontrar novas soluções; e saber, a partir das competências de cada um, tornar uma equipe criativa (RAWUNG; WURYANINGRAT; ELVINITA, 2015). É importante mencionar o requisito de gostar do que se faz indicado por uma gestora e que está alinhado ao pensamento de Amabille (1998), o qual aponta que a chave para o potencial criativo das pessoas está em trabalhar por amor e lutar para alcançar as respostas para o que as inquieta. 
Por outro lado, os gestores mencionaram - sem hesitar - a criatividade como uma competência gerencial essencial para lidar com as exigências diárias. Verificam-se tais convicções a partir de respostas rápidas e curtas após o questionamento: "Sim" [G2], "Considero, com certeza" [G4], "Sim, sim" [G6], "Eu acho que sim" [G7] "Sim, claro" [G8]. A constatação de que nas EBTs a gestão estimula os indivíduos criativos a desenvolverem suas ideias, compactua com Andersen e Kragh (2013) quando afirmam que pesssoas com alta capacidade criativa têm dificuldades para se encaixarem nas organizações tradicionais, ou seja, entre os respondentes prevaleceu à ideia de autonomia e liberdade dos colaboradores como elemento fundamental no potencial competitivo das empresas (MUZZIO; PAIVA JÚNIOR, 2018).

\subsubsection{Competências gerenciais vinculadas à criatividade em EBTs}

Após uma reflexão sobre as competências necessárias à atuação de um gestor de uma empresa de base tecnológica, resolveu-se aprofundar um pouco mais nas suas relações com a criatividade. No entanto, percebeu-se que alguns gestores incorporavam no momento da resposta algumas outras competências que não tinham sido citadas anteriormente.

Com isso, é possível observar a dificuldade que eles têm de sistematizar e incorporar, planejadamente, as competências requeridas a partir das suas atividades. Isso corrobora com a perspectiva de que ainda é um campo de estudo em formação. A natureza subjetiva da criatividade, alinhada ao seu elevado grau de componente tácito, pode dificultar a compreensão do fenômeno (MARTENS, 2011). Isso indica ainda um amplo espaço de atuação pelos gestores ao elevarem suas competências no âmbito da criatividade.

Dentre as competências mais relevantes mencionadas pelos entrevistados, destacam-se a liderança, ser visionário e a comunicação dentro da empresa, manifestas por atitudes como, por exemplo: conduzir a equipe ao alcance dos objetivos da empresa, enxergar as dificuldades individuais e coletivas e encontrar a solução mais eficiente, estar atualizado com as mudanças mercadológicas, ter planos de ação e conseguir enfrentar as incertezas; saber ouvir, filtrar as ideias e ter a humildade de dar responsabilidades e perceber que "ninguém é um superhomem" [G6] e; saber se relacionar com todos, criar um canal de comunicação bilateral e ser capaz de identificar as potencialidades e fraquezas para fortalecer os laços e as competências de cada um na empresa.

Segundo Byrne (2009), o trabalho deve ser conduzido por um estilo de liderança que fomente um link entre a estratégia e expectativas da empresa e dos indivíduos envolvidos no projeto, de modo que a satisfação de ambos seja potencializada. As várias competências evidenciam o escopo do campo e os desafios envoltos na gestão desses empreendimentos, notadamente, em seu viés criativo.

É a liderança, o cara ter liderança que é diferente do cara ser aquele chefe, gritar... liderança que é no caso saber levar o time a cumprir os objetivos da empresa, né. Não sei, mais uma vez essa questão de ter empatia, conseguir enxergar as dificuldades do seu ambiente, das pessoas e tentar solucionar da melhor forma para que o ambiente melhore. [G1]

Os gestores apontam que trabalhar estas competências de forma criativa é fundamental para fomentar ações reais para empresa, pois não adianta ter um time altamente criativo se, este potencial não é aproveitado, isto é, estariam não só desperdiçando-o, mas também 
desmotivando os colaboradores. O quadro 1 sistematiza as principais competências gerenciais em empresas de base tecnológica.

\begin{tabular}{|c|l|}
\hline COMPETÊNCIA & \multicolumn{1}{c|}{ DESCRIÇ̃̃O } \\
\hline Liderança & Conducir uma equipe para alcançar os objetivos da empresa. \\
\hline Visão de Futuro & $\begin{array}{l}\text { Estar atualizado com as mudanças mercadológicas, planejar ações e promover } \\
\text { esforços para lidar com a incertezas. }\end{array}$ \\
\hline Comunicação & $\begin{array}{l}\text { Saber ouvir, filtrar as ideias, se relacionar, criar um canal de comunicação } \\
\text { bilateral e ser capaz de identificar as potencialidades de fragilidades de cada } \\
\text { integrante da equipe para fortalecer os vínculos e alinhar as competências. }\end{array}$ \\
\hline
\end{tabular}

Fonte: Autores.

Podemos observar que essas competências estão inter-relacionadas dentro das ações gerenciais na empresa. Não se pode afirmar que uma é mais importante que a outra, porém, é possível constatar que cada competência é requerida com maior ênfase em algum momento do intenso e mutante dia-a-dia destas empresas. A recorrência com que algumas aparecem nos discursos gerenciais reforça a sua inerência no desempenho de suas atividades, mesmo que os gestores não reflitam sobre a sua utilização durante a ação.

\section{CONSIDERAÇÕES FINAIS}

Ao mesmo tempo que a nova dinâmica global exige melhores resultados das organizações, também cobra do mercado profissionais mais qualificados para suas atribuições, principalmente, na gestão do setor tecnológico. Diante deste cenário, como a criatividade pode auxiliar no desenvolvimento de competências gerenciais em EBTs?

O objetivo dessa pesquisa fora compreender a percepção dos gestores de EBTs sobre as implicações da criatividade no desenvolvimento de competências gerenciais, o que acreditamos ter sido alcançado. Os discursos dos gestores entrevistados revelaram que a criatividade, acima de tudo, contribui para melhorar as relações interpessoais dos membros da empresa, fazendo com que os gestores saibam as melhores formas de lidar com conflitos, alocar os recursos tangíveis e intangíveis, tomar decisões etc.

Outra evidência vinculada ao objetivo foi a indicação de multitarefas que os respondentes têm de desempenhar diariamente em suas empresas, principalmente àquelas ligadas à liderança, visão de futuro e comunicação. Baseado nos achados, destacamos que um fator que diferencia, por exemplo, um gestor criativo de um gestor tradicional, é que o primeiro busca estar sempre inovando nas atividades e fazendo com que seus colaboradores também potencializem sua capacidade criativa, resultando em novos horizontes para a empresa à medida que os acompanha nesse processo, reconhecendo a possibilidade de erro nas tentativas, ou seja, não punindo, mas promovendo a empatia no ambiente.

Estes aspectos conduzem a resiliência gerencial nas empresas de base tecnológica, isto é, fomenta o pensamento criativo e faz com que os gestores se adaptem melhor às exigências e externas à empresa em relação ao mercado em que atuam. Trata-se da capacidade de dar respostas positivas a circunstâncias adversas. Sendo assim, a criatividade condiciona o desenvolvimento da sensibilidade das pessoas, tanto de seus colaboradores, no desenvolvimento dos produtos a partir de percepções pessoais do que se pode oferecer a mais, quanto dos clientes, que reconhecem o verdadeiro sentido do que está sendo oferecido.

Os discursos gerenciais revelaram ainda alguns elementos intrínsecos ao comportamento gerencial, que muitas vezes são ofuscados por questões mais técnicas, tais como: perseverança, força de vontade, gosto pelo que faz, motivação, atitude, enfrentamento 
do medo, tolerância, ousadia, persistência, coragem e educação. Por isso, é imprescindível trabalhar a dimensão emocional e interpessoal nas organizações, buscando mudar hábitos indesejados e promover um ambiente aberto a escutar às pessoas (MADDUX et al., 2009).

Sobre à discussão entre competência gerencial e criatividade, ou seja, se os gestores percebem a criatividade como uma competência gerencial, os resultados revelaram que os entrevistados em sua grande maioria concordam que sim. Por outro lado, alguns gestores manifestaram-se um sentimento de dúvida, devido à dificuldade em avaliar os aspectos subjetivos inerentes à criatividade. Isso ratifica o caráter complexo e multifacetado que envolve o entendimento conceitual e processual da criatividade (SIMONTON, 2000).

No entanto, os entrevistados sugerem uma discussão balizada no desenvolvimento do potencial criativo a partir de estímulos, quando se tratam de pessoas que não "nasceram" com tal habilidade de criação. Algumas ações que podem desenvolver o potencial criativo das pessoas envolvem a capacitação, o treinamento, a participação em feiras e o contato com pessoas experientes e criativas. Além disso, a flexibilidade nas empresas deve ser estimulada, de modo que os colaboradores possam gerar novas ideias e soluções com mais abertura, ao contrário do que ocorre em empresas com gestores centralizadores.

Para novas pesquisas, outras dimensões gerenciais e/ou comportamentais podem ser investigadas no contexto da criatividade, tais como a cultura organizacional mais adequada ao contexto das EBTs, as relações de poder e o controle gerencial, além das competências emocionais demandadas para a ação gerencial em empresas de base tecnológica. Pesquisas também podem ser realizadas em outros segmentos criativos ou em outras regiões, em uma perspectiva comparativa, para o aprofundamento e consolidação de um conhecimento neste campo. 


\section{REFERÊNCIAS}

AMABILE, T. How to kill creativity. Harvard Business Review, 1998. Disponível em:< https://hbr.org/1998/09/how-to-kill-creativity>. Acesso em: 04 fev. 2016.

The social psychology of creativity: a componential conceptualization. Journal of Personality and Social Psychology, v. 45, p. 357-376, 1983.

ANDERSEN, P. H.; KRAGH, H. Managing creativity in business market relationships. Industrial Marketing Management, v. 42, p. 82-85, 2013.

ANDRON, D. R. Changing managers for a changing economy: the need for creativity and leadership. Procedia Economics and Finance, v. 6, p. 186-193, 2013.

ANTONELLO, C. S. Articulação da aprendizagem formal e informal: seu impacto no desenvolvimento de competências gerenciais. Revista Alcance, v. 12, n. 2, p. 183-210, 2005.

ARANDIGA A. V.; TORTOSA, C. V. Inteligencia emocional: aplicaciones educativas. Madrid: EOS, 2000.

ASSOCIAÇÃO NACIONAL DE ENTIDADES PROMOTORAS DE EMPREENDIMENTOS INOVADORES. INCUBADORAS E PARQUES TECNOLÓGICOS - ANPROTEC. Incubadoras e parques. Brasília, 2011. Disponível em: <http://anprotec.org.br/site/pt/incubadoras-e-parques/>. Acesso em: 16 jun. 2015.

BAER, M. Putting creativity to work: the implementation of creative ideas in organizations. Academy of Management Journal, v.55, n. 5., p.1102-1119, 2012.

BARBOSA, L. G. F.; HOFFMANN, V. E. Incubadora de empresas de base tecnológica: percepção dos empresários quanto aos apoios recebidos. Revista de Administração e Inovação, v. 10, n. 3, p. 208-229, 2013.

BARDIN, L. Análise de conteúdo. Tradução Luís Antero Reto, Augusto Pinheiro. São Paulo: Edições 70, 2011.

BELLI, M. M. Relevância do fator tecnológico no valor das empresas de tecnologia. 2008. Tese (Doutorado) - Universidade de São Paulo, São Paulo, 2008. Disponível em: < http://www.teses.usp.br/teses/disponiveis/12/12136/tde-27032009-123344/pt-br.php>. Acesso em: 17 mai.2015.

BERG, J. M. Balancing on the creative highwire: Forecasting the success of novel ideas in organizations. Administrative Science Quarterly, v. 61, n. 3, p. 433-468, 2016.

BJORNER, T.; KOFOED, L. B.; BRUUN-PEDERSEN, J. R. Creativity in project work: Students' perceptions and barriers. International Journal of Engineering Education, v.28, n. 3, p.545-553, 2012.

BOLLINGER, L.; HOPE, K.; UTTERBACK, J. A Review of Literature and Hypothesis on New Technology - Based Firms. Research Policy, v.12, p.1-14, 1983.

BÜNDCHEN, E.; ROSSETTO, C. R.; SILVA, A. B. Competências gerenciais em ação: o caso do Banco do Brasil. Revista Eletrônica de Administração (REad), Porto Alegre, v.17, n. 2, p. 396- 423, 2011.

BURRELL, G.; MORGAN, G. Sociological paradigms and organisational analysis: elements of the Sociology of Corporate Life. London: Heinemann Educational Books, 1979.

BUCKLEY, M.; STORINO, M.; SAARNI, C. Promoting emotional competence in children and adolescents: implications for school psychologists. School Psychology Quarterly, v. 18, p. 177-191, 2003.

BYRNE, C. L. et al. Examining the leaders of creative efforts: what do they do, and what do they think about? Creativity and Innovation Management, v.18, p. 256-268, 2009. 
CORTES, M. R. et al. Cooperação em empresas de base tecnológica: uma primeira avaliação baseada numa pesquisa abrangente. São Paulo Perspec. [online], v.19, n.1, p. 85-94, 2005.

DE MASI, D. Fantasia e concretude. Rio de Janeiro: Editora Sextante, 2005.

DUTRA, J. S. Competências: conceitos e instrumentos para a gestão de pessoas na empresa moderna. São Paulo: Atlas, 2004.

FELDMAN, L.B; RUTHES, R.M; CUNHA, I.C.K.O. Criatividade e inovação: competências na gestão de enfermagem. Revista Brasileira de Enfermagem (REBEn), v. 61, n. 2, p.239242, 2008.

FISCHER, A. L.; FLEURY, M.T.L.; URBAN, T.P. Cultura e competência organizacional. In: DUTRA, J. S.; FLEURY. M.T.L.; RUAS, R. (Org.). Competências: conceitos, métodos e experiências. São Paulo: Atlas, 2008. p. 106-124.

LE BOTERF, G. Desenvolvendo a competência dos profissionais. Porto Alegre: Artmed, 2003.

LEE, D. S. et al. An analysis of shared leadership, diversity, and team creativity in an elearning environment. Computers in Human Behavior, v.42, p.47-56, 2015.

MADDUX, W. W. et al. Toward a more complete understanding of the link between multicultural experience and creativity. American Psychologist, v.64, n. 2, p.156-158, 2009.

MARCOVITCH, J., SANTOS, S. A., DUTRA, I. Criação de empresas de base tecnológica. Revista de administração, v. 21, n. 2, p. 3-9, 1986.

MARTENS, Y. Creative workplace: instrumental and symbolic support for creativity. Facilities, v. 29, p. 63-79, 2011.

MELLO, S. C. B. et al. Orientação empreendedora e competências de marketing no desempenho organizacional: um estudo em empresas de base tecnológica. Organizações \& Sociedade, v.13, n.36, p. 185-202.

MERRIAM, S. B. Qualitative Research: a guide to design and interpretation. San Francisco: Jossey-Bass, 2009.

MIETZNER, D.; KAMPRATH, M. A competence portfolio for professionals in the creative industries. Creativity and Innovation Management, v.22, p.1-15, 2013.

MINTZBERG, H. Managing: desvendando o dia a dia da gestão. São Paulo: Bookman, 2010. MUMFORD, M. D; GUSTAFSON, S. B. Creativity syndrome: integration, application, and innovation. Psychological Bulletin, v.103, p. 27-43, 1988.

MUZZIO, H.; PAIVA JÚNIOR, F. G. Organizational Creativity Management: Discussion Elements. Revista de Administração Contemporânea, v. 22, n. 6, 922-929, 2018.

PEREIRA, A. L. C. Da lagarta à borboleta: as competências em ação dos gestores técnicosadministrativos das instituições federais de ensino superior do Nordeste brasileiro. 2010.Dissertação (Mestrado em Administração) - Universidade Federal da Paraíba, João Pessoa, 2010.

PEREIRA, A. L. C.; SILVA, A. B. As competências gerenciais nas instituições federais de educação superior. Cad. EBAPE.BR [online]. v.9, n. esp. 1, pp. 627-647, 2011.

PINHEIRO, A. C. F. B.; BURINI, E.R.V. A criatividade como competência básica para inovação tecnológica na transformação do conhecimento em riqueza. In: CONGRESSO BRASILEIRO DE EDUCAÇÃO EM ENGENHARIA, 34, 2006, Passo Fundo. Anais... Passo Fundo, 2006.

PORTER, M. The competitive advantage of nations. New York: The Free Press Inc, 1990. PRAHALAD, C.K.; HAMEL, G. Competindo pelo futuro: estratégias inovadoras para obter o controle do seu setor e criar os mercados de amanhã. Rio de Janeiro: Campus, 1995. 
RAWUNG, F. H.; WURYANINGRAT, N. F.; ELVINITA L. E. The influence of transformational and transactional leadership on knowledge sharing: an empirical study on small and medium businesses in Indonesia. Asian Academy of Management Journal, v. 20, n. 1, p. 123-145, 2015.

RUAS, R. Desenvolvendo Competências Gerenciais e Contribuição da Aprendizagem Organizacional. In: FLEURY, M. T. L.; OLIVEIRA Jr. M. M. (Org.) Gestão Estratégica do Conhecimento: integrando aprendizagem, conhecimento e competências. São Paulo: Atlas, 2001, Cap. 8, pp. 242-267.

RUAS, R.; ANTONELLO, C. S.; BOFF, L. H. (Orgs.). Os novos horizontes da gestão: Aprendizagem organizacional e competências. Porto Alegre: Bookman, 2005.

SARQUIS, A. B. et al. Fatores de Influência no Processo de Inovação em Empresas de Base Tecnológica. Revista Catarinense da Ciência Contábil, v. 14, n. 43, p. 38-50, 2015.

SCHACHTER, M. E. et al. Disentangling competences: interrelationships on creativity, innovation and entrepreneurship. Thinking Skills and Creativity, v.16, p.27-39, 2015.

SEO, Y.W.; CHAE, S. W.; LEE, K.C. The impact of absorptive capacity, exploration, and exploitation on individual creativity: moderating effect of subjective well-being. Computers in Human Behavior, v.42, p.68-82, 2015.

SILVA, A. B. Como os gerentes aprendem. São Paulo: Saraiva, 2009.

SIMONTON, D. K. Creativity: cognitive, personal, developmental and social aspects. American Psychologist, v.55, p.151-158, 2000.

STRAUSS, A.; CORBIN, J. Pesquisa qualitativa: técnicas e procedimentos para o desenvolvimento de teoria fundamentada. Tradução Luciane de Oliveira da Rocha. 2. ed. Porto Alegre: Artmed, 2008.

SUCHMAN, R. J. Idea book for geological inquiry. Trilium Press, 1981.

VERGARA, S. C. Métodos de coleta de dados no campo. São Paulo: Atlas, 2009.

WOLFFENBÜTTEL, A. P. Avaliação do processo de interação universidade-empresa em incubadoras universitárias de empresas: um estudo de caso na incubadora de empresas de base tecnológica da UNISINOS. 2001. de mestrado não publicada - Universidade Federal do Rio Grande do Sul, Porto Alegre. 2001.

ZARIFIAN, P. Objetivo competência: por uma nova lógica. São Paulo: Atlas, 2001. 